\title{
Acute optic neuritis and the prognosis for multiple sclerosis
}

\author{
W. M. HUTCHINSON ${ }^{1}$
}

From the Royal Victoria Hospital, Grosvenor Road, Belfast, N. Ireland

SYNOPSIS In a retrospective survey of acute optic neuritis 144 cases in adults were found and, of these, 127 were reviewed, five had died of causes related to multiple sclerosis, and 12 were lost to follow-up. There was a statistically significant seasonal variation in the incidence of optic neuritis. When the life-table method of analysis was used, the probability of developing multiple sclerosis rises to $78 \% 15$ years after an episode of optic neuritis. At review, $49(73 \%)$ of the 67 patients with multiple sclerosis were independent and leading active lives.

While it is generally agreed that the major cause of acute optic neuritis in adults is multiple sclerosis (McAlpine, 1972), there is wide variation in the reported incidence of multiple sclerosis after optic neuritis. Kurland et al. (1966) found that $13 \%$ of U.S. Army servicemen with optic neuritis followed up for 12 to 18 years developed multiple sclerosis, whereas Bradley and Whitty (1968) in Oxford found that $51 \%$ of their patients later developed definite or probable multiple sclerosis. McAlpine (1964), adapting the figures published by Lynn (1959), calculated that $85 \%$ of her patients with optic neuritis followed up for at least five years had developed multiple sclerosis. Many reports include patients with other signs of multiple sclerosis at the onset of optic neuritis and therefore do not contribute to this problem.

It is the purpose of this study to clarify the position as to the prognosis of patients with acute optic neuritis with regard to the later development of multiple sclerosis. The epidemiological characteristics of multiple sclerosis in Northern Ireland have been studied for many years (Allison and Millar, 1954; Millar, 1971) and this area has the advantage of a well-defined, relatively static population of $1 \frac{1}{2}$ million with extensive neurological and ophthalmological services.

1 Present address: The National Hospital, Queen Square, London WC1 3BG.

(Accepted 15 October 1975.)

\section{METHODS}

PATIENTS All patients with the diagnosis of acute optic neuritis or multiple sclerosis initiated by an episode of acute optic neuritis during the period 1960-74 were selected for review. Cases were obtained from the diagnostic index systems of all major hospitals in Northern Ireland and patients were also referred from the consulting neurological and ophthalmological physicians in those hospitals.

Acute optic neuritis was defined clinically as the acute or subacute onset of blurred vision in one or both eyes associated with a central, centrocaecal, or paracentral scotoma, and with no demonstrable local cause such as ischaemia, tumour, or retinal lesion. Patients with optic neuritis were excluded from the series if there were other associated neurological symptoms or signs, or if these had been present in the past. Patients were further classified as having either unilateral, recurrent, or bilateral optic neuritis. Unilateral optic neuritis was defined as occurring when an eye was involved only once, bilateral optic neuritis when both eyes were involved simultaneously or within a period of two weeks and recurrent optic neuritis when repeated attacks affected one or both eyes over an interval greater than two weeks.

A total of 152 patients fulfilled these criteria in the 15 year period and, of these, eight children under 12 years of age were excluded from the main study. Of the remaining 144 patients, five had died of causes related to multiple sclerosis, 12 were lost to follow-up, and 127 patients were reviewed. A careful history was taken from each patient and a full general and neurological examination was performed. 
Visual acuity, corrected if necessary, was recorded using Jaeger and Snellen charts. Blood was taken for immunological studies and patients seen during an acute attack were admitted to hospital for examination of the CSF.

Patients with evidence of multiple sclerosis were assigned as either probable or possible cases according to the criteria of Millar (1971). The degree of disability was assessed and scored on a 10 point scale as described by Kurtzke (1970).

\section{RESULTS}

A total of 144 patients presented with acute optic neuritis during the 15 year period and $57 \%$ experienced unilateral attacks, 24\% recurrent and $19 \%$ bilateral (Table 1 ). Women formed $73 \%$ of the whole series and a similar preponderance is noted in all three subgroups with the highest female percentage in the bilateral cases $(82 \%)$.

The age of onset ranged between 14 and 59 years but $74 \%$ of cases occurred between the ages of 20 and 50 years (Fig. 1). The median age of onset of acute optic neuritis was 29 years for the whole series and for patients with unilateral and recurrent optic neuritis but was slightly lower at 26 years for patients with bilateral optic neuritis.

A seasonal variation was noted in the incidence of optic neuritis (Fig. 2). A total of 193 attacks of optic neuritis were recorded in the 144 patients (82 unilateral, 27 bilateral, and 84 recurrent). The months of April to July had a high attack rate with a low rate in August to November. Allowing for the differences in the lengths of months, this seasonal variation is statistically significant $\left(\chi^{2}=23.539\right.$, D.F. $=11$, $P<0.02$ ).

The onset of the visual symptoms was de-

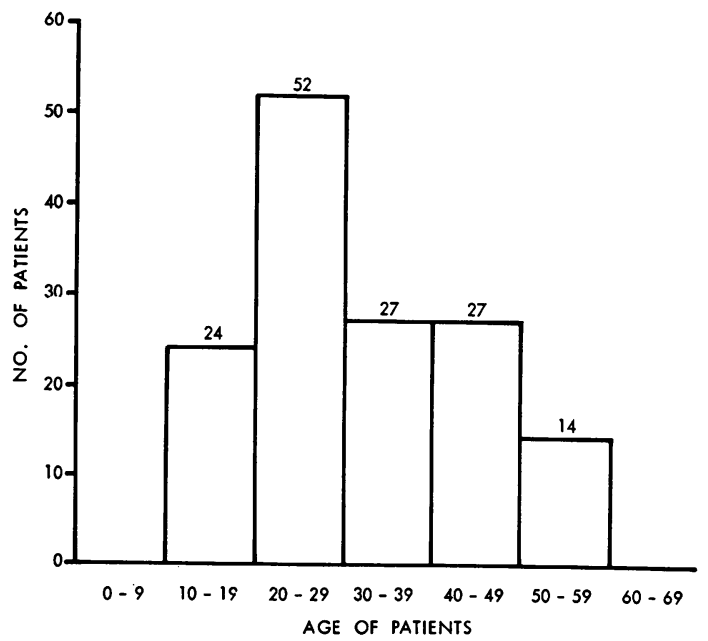

FIG. 1 Distribution by age in years of the 144 patients presenting with optic neuritis.

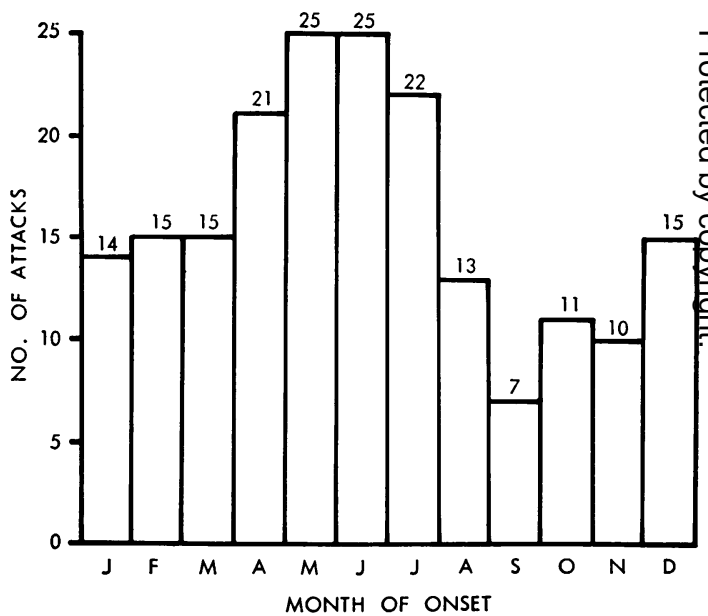

FIG. 2 Distribution of 193 attacks of optic neuritis by month of onset over a 15 year period.

TABLE 1

DETAILS OF PATIENTS IN SURVEY

\begin{tabular}{|c|c|c|c|c|c|c|c|c|c|}
\hline \multirow{3}{*}{$\begin{array}{l}\text { Type of optic } \\
\text { neuritis }\end{array}$} & \multicolumn{2}{|c|}{ Patients } & \multirow{3}{*}{$\begin{array}{l}\text { Female: male } \\
\text { ratio }\end{array}$} & \multirow{3}{*}{$\begin{array}{l}\text { Lost to } \\
\text { review }\end{array}$} & \multirow{3}{*}{$\begin{array}{c}\text { Deaths } \\
\text { due to } \\
M S\end{array}$} & \multirow{3}{*}{$\begin{array}{l}\text { Patients } \\
\text { reviewed } \\
\quad(\text { no. })\end{array}$} & \multirow{2}{*}{\multicolumn{2}{|c|}{$\begin{array}{c}\text { Number } \\
\text { developing } \\
M S\end{array}$}} & \multirow{3}{*}{$\begin{array}{c}\text { Mean period } \\
\text { of } \\
\text { follow-up } \\
\text { (months) }\end{array}$} \\
\hline & (no.) & $(\%)$ & & & & & & & \\
\hline & & & & & & & (no.) & $(\%)$ & \\
\hline $\begin{array}{l}\text { Unilateral } \\
\text { Recurrent } \\
\text { Bilateral }\end{array}$ & $\begin{array}{l}82 \\
35 \\
27\end{array}$ & $\begin{array}{l}57 \\
24 \\
19\end{array}$ & $\begin{array}{l}2.7: 1 \\
1.9: 1 \\
4.4: 1\end{array}$ & $\begin{array}{l}7 \\
4 \\
1\end{array}$ & $\frac{4}{1}$ & $\begin{array}{l}71 \\
31 \\
25\end{array}$ & $\begin{array}{l}33 \\
17 \\
17\end{array}$ & $\begin{array}{l}44 \\
55 \\
65\end{array}$ & $\begin{array}{r}77.2 \\
132.8 \\
77.2\end{array}$ \\
\hline Total & 144 & 100 & $2.7: 1$ & 12 & 5 & 127 & 67 & 51 & 90.3 \\
\hline
\end{tabular}


scribed as sudden in $20 \%$ of patients, gradually worsening over days in $65 \%$, and progressive over several weeks in $15 \%$. The severity of reduction of visual acuity varied between $6 / 9$ to loss of perception of light, but there was no relationship between the severity of visual loss and the degree of recovery. Pain was present in $77 \%$ of patients and frequently preceded the disturbance of visual acuity.

The optic disc was described as normal in $60 \%$ of patients, blurred in $18 \%$, pale in $5 \%$, and papillitis was present in $17 \%$. There was no relationship between the presence or absence of disc oedema and the later development of multiple sclerosis.

Visual acuity at follow-up was recorded using a Snellen chart. Good vision was taken as $6 / 6$ or $6 / 9$, fair vision $6 / 12$ to $6 / 36$, and poor vision as $6 / 60$ or less. Patients with recurrent attacks fared less well with poor visual acuity in $19 \%$ of the affected eyes, whereas $13 \%$ of the eyes which sustained unilateral attacks and $8 \%$ with bilateral attacks resulted in poor visual acuity

TABLE 2

ASSESSMENT OF VISUAL ACUITY AT FOLLOW-UP

\begin{tabular}{|c|c|c|c|c|c|c|c|c|}
\hline \multirow{3}{*}{$\begin{array}{l}\text { Degree of } \\
\text { recovery of } \\
\text { visual acuity }\end{array}$} & \multicolumn{8}{|c|}{ Number of affected eyes in relation to type of $O N$} \\
\hline & \multicolumn{2}{|c|}{ Unilateral } & \multicolumn{2}{|c|}{ Recurrent } & \multicolumn{2}{|c|}{ Bilateral } & \multicolumn{2}{|c|}{ Total } \\
\hline & {$[($ no. $)$} & $(\%)$ & (no.) & $(\%)$ & (no.) & $(\%)$ & (no.) & $(\%)$ \\
\hline $\begin{array}{l}\text { Good } \\
\text { Fair } \\
\text { Poor }\end{array}$ & $\begin{array}{r}51 \\
11 \\
9\end{array}$ & $\begin{array}{l}72 \\
15 \\
13\end{array}$ & $\begin{array}{l}32 \\
12 \\
10\end{array}$ & $\begin{array}{l}59 \\
22 \\
19\end{array}$ & $\begin{array}{r}36 \\
10 \\
4\end{array}$ & $\begin{array}{r}72 \\
20 \\
8\end{array}$ & $\begin{array}{r}119 \\
33 \\
23\end{array}$ & $\begin{array}{l}68 \\
19 \\
13\end{array}$ \\
\hline Total & 71 & 100 & 54 & 100 & 50 & 100 & 175 & 100 \\
\hline
\end{tabular}

ON: acute optic neuritis.
(Table 2). Despite this, only two patients in this series were left with a severe visual disability requiring a change from their previous occupation.

The CSF was examined in 31 patients during the acute attack and in $11(35 \%)$ there was an abnormality consisting of a mild lymphocytosis associated with a paretic Lange curve in four. When reviewed, four patients with an initially abnormal CSF and five patients with a normal CSF had developed multiple sclerosis. There was no evidence of earlier dissemination of lesions or a more severe clinical course in those patients with a CSF pleocytosis.

A total of 127 patients was reviewed, a further five had died, and 12 were lost to follow-up because of emigration. The five patients who died in the follow-up period were all welldocumented cases of multiple sclerosis and were all severely disabled with secondary infections leading to death. These five patients have therefore been included with the reviewed patients making a total of 132 cases of acute optic neuritis, of whom $67(51 \%)$ developed further symptoms and signs of multiple sclerosis. When assessment was made by the type of initial attack, it was found that $44 \%$ of unilateral, $65 \%$ of bilateral, and $55 \%$ of recurrent cases of optic neuritis had developed multiple sclerosis by the time of review (Table 1). With regard to age at onset of acute optic neuritis, $40 \%$ of patients under 25 years, $62 \%$ aged 25 to 44 years and $40 \% 45$ years and older had developed multiple sclerosis at review.

The mean duration of follow-up for the 132 cases was 90.3 months but this varied between

TABLE 3

PROBABILITY OF DEVELOPING MULTIPLE SCLEROSIS AFTER OPTIC NEURITIS

\begin{tabular}{|c|c|c|c|c|c|c|c|}
\hline \multirow[t]{2}{*}{ Year } & \multirow{2}{*}{$\begin{array}{c}\text { No. at risk } \\
\text { at start of } \\
\text { year }\end{array}$} & \multirow{2}{*}{$\begin{array}{c}\text { Withdrawals } \\
\text { during } \\
\text { year }\end{array}$} & \multirow{2}{*}{$\begin{array}{c}\text { No. } \\
\text { developing } \\
\text { MS during } \\
\text { year }\end{array}$} & \multicolumn{4}{|c|}{$\begin{array}{c}\text { Percent probability of developing multiple sclerosis } \\
\text { by end of year }\end{array}$} \\
\hline & & & & Unilateral & Recurrent & Bilateral & Total \\
\hline $\begin{array}{c}0-1 \\
1-2 \\
2-3 \\
3-4 \\
4-5 \\
9-10 \\
14-15\end{array}$ & $\begin{array}{r}132 \\
99 \\
85 \\
73 \\
61 \\
19 \\
6\end{array}$ & $\begin{array}{r}9 \\
4 \\
5 \\
7 \\
10 \\
1 \\
1\end{array}$ & $\begin{array}{r}24 \\
10 \\
7 \\
5 \\
4 \\
2 \\
2\end{array}$ & \begin{tabular}{l|}
18.3 \\
23.0 \\
32.8 \\
36.4 \\
40.8 \\
58.9 \\
76.5
\end{tabular} & $\begin{array}{l}12.9 \\
19.3 \\
19.3 \\
26.5 \\
34.2 \\
61.2 \\
73.7\end{array}$ & $\begin{array}{l}27.5 \\
48.2 \\
52.7 \\
57.7 \\
57.7 \\
79.3 \\
79.3\end{array}$ & $\begin{array}{l}19.0 \\
27.3 \\
33.5 \\
38.3 \\
42.7 \\
64.2 \\
77.8\end{array}$ \\
\hline
\end{tabular}


the three types of optic neuritis (Table 1). In view of the differing periods of follow-up between the three groups and between patients, the life-table method of analysis is best suited to demonstrate the probability of developing multiple sclerosis for any given time after acute optic neuritis (Table 3).

Patients with bilateral optic neuritis have a consistently higher probability of developing multiple sclerosis over the first 10 years after an attack than those patients with unilateral or recurrent optic neuritis (Fig. 3). Patients with recurrent optic neuritis have a similar probability of developing multiple sclerosis over the whole 15 year period as patients with unilateral optic neuritis. When all patients are considered, the probability of developing multiple sclerosis rises to $77.8 \% 15$ years after acute optic neuritis. Of the 67 patients with multiple sclerosis, 39 cases were classified as probable $(58 \%)$ and 28 as possible $(42 \%)$. The percentage of probable cases was similar in all three groups.

Patients with multiple sclerosis at review were assessed as to functional disability using a 10 point scale described by Kurtzke (1970). On this scale grades 1-4 include patients with no to moderate disability who are relatively independent. Grades 5-9 include patients with increasing disability up to totally helpless patients. Grade 10 is used for death due to multiple sclerosis. Forty-nine $(73 \%)$ of the 67 patients with multiple sclerosis were independent and leading active lives and $18(27 \%)$ were more severely disabled or dead (Table 4). When disability is related to the initial type of attack of optic neuritis, it is clear that the bilateral cases do less well; $47 \%$ of these patients were severely disabled or dead, whereas only $24 \%$ of the unilateral and $12 \%$ of the recurrent cases were similarly affected. This is despite the fact that the average follow-up period for the bilateral cases ( 77 months) was less than that for the other two groups.

Multiple sclerosis may be characterized clinically by disease activity into remitting, inactive, or chronic progressive types of illness. Patients in the present series were thus classified (Table 5) and the only difference between the three groups which might explain the differences in the degree of disability is that fewer of the bilateral optic

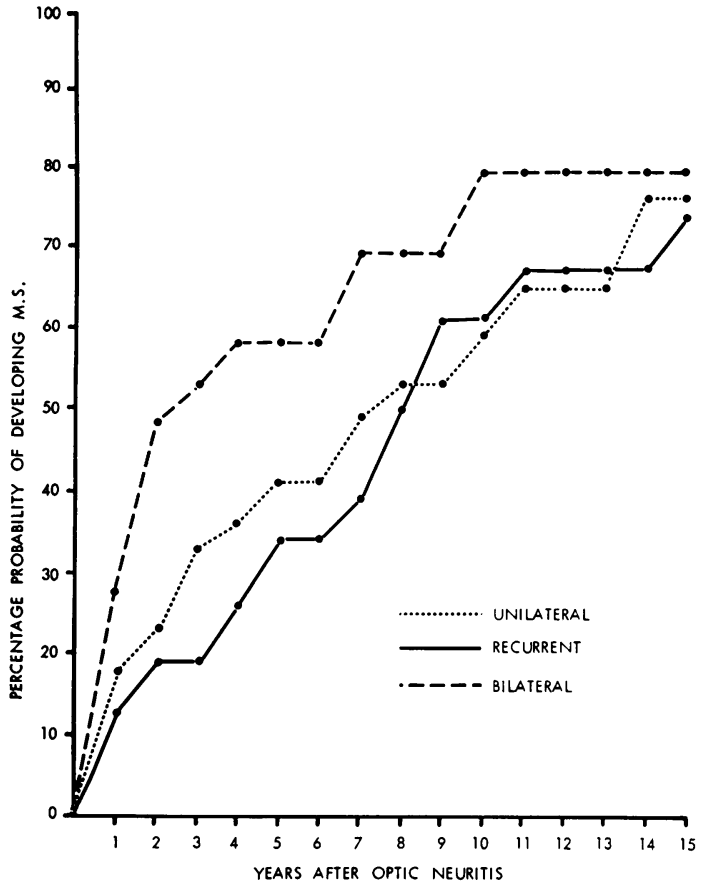

FIG. 3 The percentage probability of developing multiple sclerosis for up to 15 years after an attack of unilateral, recurrent, or bilateral optic neuritis.

TABLE 4

GRADES OF DISABILITY OF PATIENTS WITH MULTIPLE SCLEROSIS AT REVIEW

\begin{tabular}{|c|c|c|c|c|c|c|c|c|}
\hline \multirow[t]{3}{*}{ Grade } & \multicolumn{8}{|c|}{ No. of patients in each grade } \\
\hline & \multicolumn{2}{|c|}{ Unilateral } & \multicolumn{2}{|c|}{ Recurrent } & \multicolumn{2}{|c|}{ Bilateral } & \multicolumn{2}{|c|}{ Total } \\
\hline & (no.) & $(\%)$ & (no.) & $(\%)$ & (no.) & $(\%)$ & (no.) & $(\%)$ \\
\hline $\begin{array}{r}1 \\
2 \\
3 \\
4 \\
5 \\
6 \\
7 \\
8 \\
9 \\
10\end{array}$ & $\begin{array}{r}15 \\
3 \\
4 \\
3 \\
\frac{2}{2} \\
\frac{2}{4}\end{array}$ & 24 & $\begin{array}{r}10 \\
2 \\
2 \\
1 \\
1 \\
1 \\
- \\
-\end{array}$ & 12 & $\begin{array}{l}4 \\
4 \\
1 \\
1 \\
3 \\
1 \\
1 \\
1 \\
1\end{array}$ & 47 & $\left.\begin{array}{r}29 \\
9 \\
7 \\
4 \\
2 \\
6 \\
1 \\
3 \\
1 \\
5\end{array}\right)$ & $\begin{array}{l}73 \\
\quad 27\end{array}$ \\
\hline $\begin{array}{l}\text { Mean } \\
\text { follow-up } \\
\text { period } \\
\text { (months) }\end{array}$ & 99.3 & & 99.1 & & 77.0 & & 93.4 & \\
\hline
\end{tabular}

neuritis group were in an inactive phase of their illness.

In view of the hypothesis that the tendency to multiple sclerosis may be related to events occur- 
ring before the age of 16 years (Millar, 1971) and the evidence that in Northern Ireland agricultural and other land-workers form a significantly higher proportion of the population of multiple sclerosis patients than of the general population (Millar, J. H. D., personal communication), it was decided to examine the distribution of occupations of fathers of patients with acute optic neuritis. No significant difference was found in the distribution of paternal occupations by socioeconomic grouping between the 127 patients reviewed with optic neuritis and the male population aged 45 years and over in the 1961 Northern Ireland census.

TABLE 5

CLINICAL COURSE OF MULTIPLE SCLEROSIS AFTER OPTIC NEURITIS

\begin{tabular}{|c|c|c|c|c|c|c|}
\hline \multirow[t]{3}{*}{ Course } & \multicolumn{6}{|c|}{ Type of optic neuritis } \\
\hline & \multicolumn{2}{|c|}{ Unilateral } & \multicolumn{2}{|c|}{ Recurrent } & \multicolumn{2}{|c|}{ Bilateral } \\
\hline & (no.) & $(\%)$ & (no.) & $(\%)$ & (no.) & $(\%)$ \\
\hline $\begin{array}{l}\text { Remitting } \\
\text { Chronic progressive } \\
\text { Inactive } \\
\text { Total }\end{array}$ & $\begin{array}{r}16 \\
12 \\
5 \\
33\end{array}$ & $\begin{array}{r}49 \\
36 \\
15 \\
100\end{array}$ & $\begin{array}{r}9 \\
5 \\
3 \\
17\end{array}$ & $\begin{array}{r}53 \\
29 \\
18 \\
100\end{array}$ & $\begin{array}{r}9 \\
7 \\
1 \\
17\end{array}$ & $\begin{array}{r}53 \\
41 \\
6 \\
100\end{array}$ \\
\hline
\end{tabular}

\section{DISCUSSION}

Acute optic neuritis as the first sign of multiple sclerosis is a useful clinical entity for several reasons: the time of onset of symptoms can be accurately stated, patients usually present early for medical attention, the severity of the acute attack and the effect of therapy can be measured, and immunological studies may be made in an early active stage of demyelination.

This study of 132 patients with optic neuritis has shown that the probability of developing multiple sclerosis increases steadily with time, so that 15 years after the onset $78 \%$ of patients may become so affected. Although only $51 \%$ of the reviewed patients showed evidence of multiple sclerosis, because of the differing periods of follow-up for each patient, the life-table method of analysis gives a more accurate indication of the likelihood of developing multiple sclerosis for any given period after acute optic neuritis. This figure of $78 \%$ at 15 years approaches closely the figure of $85 \%$ cases of multiple sclerosis quoted by McAlpine (1964) for patients followed up from five to 29 years after their acute optic neuritis. The reported low incidence of multiple sclerosis after optic neuritis particularly in America (Taub and Rucker, 1954, 32\%; Collis, 1965, 36\%; Kurland et al., 1966, 13\%; Percy et al., 1972, 17\%) is at variance with findings of the present study and the reports of several European series (Bradley and Whitty, $1968,51 \%$; Rose, 1972, 58\%; Nikoskelainen and Riekkinen, 1974, 63\%). This variation in the reported incidence of multiple sclerosis after acute optic neuritis may be partly explained by differing diagnostic criteria. It is possible that if the follow-up period in this study were extended to 20 or 30 years after acute optic neuritis, the percentage of patients developing multiple sclerosis would rise further. Adie (1932) has reported one patient where an interval of 24 years existed between the onset of optic neuritis and multiple sclerosis, and several other series include patients who have developed multiple sclerosis over 15 years after optic neuritis (Kurland et al., 1966; Bradley and Whitty, 1968).

Despite the high incidence of further demyelination in this series of patients, there are several differences between them and the known characteristics of multiple sclerosis in general. The average female:male sex ratio in 10 incidence studies of multiple sclerosis is 1.9:1 (Acheson, 1972), whereas in the present study this ratio is $2.7: 1$. A similar preponderance of female patients has been reported in other surveys of optic neuritis (Percy et al., 1972; Leibowitz et al., 1966; Bradley and Whitty, 1967) and must reflect a predisposition for early optic nerve involvement in this sex.

A seasonal variation in relation to the month of onset of optic neuritis is present in this series with an increased number of attacks in the months April to July. A similar trend of increased frequency of acute optic neuritis in the spring and summer months has been noted in two other studies (Taub and Rucker, 1954; Bradley and Whitty, 1967). This seasonal variation suggests an infectious or para-infectious agent in the pathogenesis of optic nerve de- 
myelination. There is no seasonal variation in the onset of multiple sclerosis and this has been raised as evidence against an infectious aetiology in this disease. However, the exact timing of the onset of multiple sclerosis with cord and brainstem symptoms can be extremely difficult, whereas the onset of acute optic neuritis can be easily timed in most patients, possibly because of the sensitivity of the papillomacular bundle to small foci of demyelination.

When assessed by functional disability at review, $73 \%$ of the 67 patients with multiple sclerosis were independent and leading active lives and only $27 \%$ were disabled or dead. Comparison may be made between the present series and 311 patients with multiple sclerosis followed up by Bauer et al. (1965) for six to 10 years of whom $50.2 \%$ were in independent grades and $49.8 \%$ were incapacitated or dead. Other studies have shown a similar good prognosis for multiple sclerosis developing after acute optic neuritis in contrast with patients with multiple sclerosis of other onset. Bradley and Whitty (1968) found that $81 \%$ of their patients with multiple sclerosis were unrestricted after 10 years and Nikoskelainen and Riekkinen (1974) reported $74 \%$ unrestricted after 11 to 20 years. It has been suggested by Mackay and Hirano (1967) that this benign prognosis for multiple sclerosis after acute optic neuritis simply reflects more accurately the true nature of the disease in the community, which a follow-up study of this type will detect, while only more severely disabled patients are likely to be reported in studies based on hospital outpatient attendances. While this may be partly true of the present series, it is to be noted that McAlpine (1961), in a long-term follow-up of 241 patients with multiple sclerosis, found that $57 \%$ of those whose first symptom was optic neuritis were unrestricted, whereas only $27 \%$ of those with some other onset were in that category.

As well as exaggerating the severity of multiple sclerosis, it is also evident that prevalence surveys based on patients referred to hospitals underestimate the frequency of multiple sclerosis in the community. In this study 10 previously undiagnosed patients were seen with definite pathological pyramidal tract and brain-stem signs and with little or no disability.
Acute optic neuritis occurring after the age of 45 years may be ischaemic rather than demyelinating in aetiology and care was taken in the selection of the patients to exclude cases of ischaemic optic neuritis. Of the 25 patients over the age of 45 years, $40 \%$ later developed evidence of multiple sclerosis. It is to be noted that the oldest patient in this survey sustained bilateral optic neuritis at the age of 59 years and 18 months later a chronic progressive spastic ataxic paraparesis with euphoria ensued.

Bilateral optic neuritis in adults would appear to have a worse prognosis than either unilateral or recurrent optic neuritis for the development of earlier and more disabling multiple sclerosis. The same is not true for bilateral optic neuritis of childhood (Meadows, 1969) and of six children seen in the course of, but not included in, this study none had developed multiple sclerosis over periods of up to 14 years' follow-up.

Of 31 patients who had a CSF examination during the acute attack only 11 showed an abnormality. There was no evidence of any relationship between the presence of an initial CSF pleocytosis and the later development of multiple sclerosis. Link et al. (1973), studying the CSF of patients with acute optic neuritis, have shown that that presence of oligoclonal IgG (such as occurs in $94 \%$ of patients with multiple sclerosis (Link and Müller, 1971)) was significantly associated with the presence of a CSF pleocytosis. The relevance of these findings to the future development of multiple sclerosis is as yet unknown. The present study suggests that the likelihood of developing multiple sclerosis soon after acute optic neuritis varies according to the type of initial attack but the risk is not related to the presence or absence of a CSF abnormality.

I am grateful to Dr Desmond Merrett for advice on statistical methods and I wish to thank all the consultant neurologists and ophthalmologists who gave valuable help during the course of this study, in particular, Dr J. H. D. Millar, Dr M. Swallow, Dr J. A. Lyttle, Professor D. Archer, and Mr C. Maguire. I would like also to thank Mrs E. Keating and Mrs A. Ward for typing this manuscript. The author is grateful for a research grant from the Eastern Health and Social Services Board from its Endowment Funds which has enabled him to carry out this work. 


\section{REFERENCES}

Acheson, E. D. (1972). The epidemiology of multiple sclerosis. In Multiple Sclerosis: a Reappraisal, pp. 3-80. Edited by D. McAlpine, C. E. Lumsden, and E. D. Acheson. Churchill Livingstone: Edinburgh.

Adie, W. J. (1932). The aetiology and symptomatology of disseminated sclerosis. British Medical Journal, 2, 997-1000.

Allison, R. S., and Millar, J. H. D. (1954). Prevalence and familial incidence of disseminated sclerosis. Ulster Medical Journal, 23, suppl. 2, pp. 1-92.

Bauer, H. J., Firnhaber, W., and Winkler, W. (1965). Prognostic criteria in multiple sclerosis. Annals of the New. York Academy of Sciences, 122, 542-551.

Bradley, W. G., and Whitty, C. M. W. (1967). Acute optic neuritis: its clinical features and their relation to prognosis for recovery of vision. Journal of Neurology, Neurosurgery, and Psychiatry, 30, 531-538.

Bradley, W. G., and Whitty, C. M. W. (1968). Acute optic neuritis: prognosis for development of multiple sclerosis. Journal of Neurology, Neurosurgery, and Psychiatry, 31, 10-18.

Collis, W. J. (1965). Acute unilateral retrobulbar neuritis. Archives of Neurology (Chic.), 13, 409-412.

Kurland, L. T., Beebe, G. W., Kurtzke, J. F., Nagler, B., Auth, T. L., Lessel, S., and Nefzger, M. D. (1966). Studies on the natural history of multiple sclerosis. Acta Neurologica Scandinavica, suppl. 19, pp. 157-176.

Kurtzke, J. F. (1970). Neurologic impairment in multiple sclerosis and the disability status scale. Acta Neurologica Scandinavica, 46, 493-512.

Leibowitz, U., Alter, M., and Halpern, L. (1966). Clinical studies of multiple sclerosis in Israel. 4. Optic neuropathy and multiple sclerosis. Archives of Neurology (Chic.), 14, 459-466.

Link, H., and Müller, R. (1971). Immunoglobulins in multiple sclerosis and infections of the nervous system. Archives of Neurology (Chic.), 25, 326-344.

Link, H., Norrby, E., and Olsson, J.-E. (1973). Immunoglobulins and measles antibodies in optic neuritis. New England Journal of Medicine, 289, 1103-1107.

Lynn, B. H. (1959). Retrobulbar neuritis. Transactions of the Ophthalmological Societies of the United Kingdom, 79, 701716.

McAlpine, D. (1961). The benign form of multiple sclerosis. Brain, 84, 186-203.

McAlpine, D. (1964). The benign form of multiple sclerosis: results of a long-term study. British Medical Journal, 2, 1029-1032.

McAlpine, D. (1972). Optic (retrobulbar) neuritis. In Multiple Sclerosis: a Reappraisal, pp. 148-163. Edited by D. McAlpine, C. E. Lumsden, and E. D. Acheson. Churchill Livingstone: Edinburgh.

Mackay, R. P., and Hirano, A. (1967). Forms of benign multiple sclerosis. Archives of Neurology (Chic.), 17, 588600.

Meadows, S. P. (1969). Retrobulbar and optic neuritis in childhood and adolescence. Transactions of the Ophthalmological Societies of the United Kingdom, 89, 603-638.

Millar, J. H. D. (1971). Multiple Sclerosis: a Disease Acquired in Childhood. Thomas: Springfield, Ill.

Nikoskelainen, E., and Riekkinen, P. (1974). Optic neuritisa sign of multiple sclerosis or other diseases of the central nervous system. Acta Neurologica Scandinavica, 50, 690718.

Percy, A. K., Norbrega, F. T., and Kurland, L. T. (1972). Optic neuritis and multiple sclerosis. Archives of Ophthalmology, 87, 135-139.

Rose, F. C. (1972). The aetiology of optic neuritis. Monographs in Human Genetics, 6, 196.

Taub, R. G., and Rucker, C. W. (1954). The relationship of optic neuritis to multiple sclerosis. American Journal of Ophthalmology, 37, 494-497. 